\title{
Growth trends and forecasting of fish production in Assam, India using ARIMA model
}

\author{
Anil Kumar Yadav * \\ ICAR-Central Inland Fisheries Research Institute, Regional Centre, Guwahati-781006 \\ (Assam), India \\ Kishore Kumar Das \\ Department of Statistics, Gauhati University, Guwahati-781034 (Assam), India \\ Pronob Das \\ ICAR-Central Inland Fisheries Research Institute, Regional Centre, Guwahati-781006 \\ (Assam), India \\ Rohan Kumar Raman \\ ICAR Research Complex for Eastern Region, Patna- 800014 (Bihar), India \\ Jeetendra Kumar \\ ICAR-Central Inland Fisheries Research Institute, Regional Centre, Prayagraj-700120 (Uttar \\ Pradesh), India \\ Basanta Kumar Das \\ ICAR-Central Inland Fisheries Research Institute, Barrackore, Kolkata-700120 (West Bengal), \\ India \\ *Corresponding author. E. mail: yadav.anil.stats@gmail.com
}

\section{Article Info}

https://doi.org/10.31018/ jans.v12i3.2353

Received: August 6, 2020

Revised: September 4, 2020

Accepted: September 8, 2020

\section{How to Cite}

Yadav, A. K. et al. (2020). Growth trends and forecasting of fish production in Assam, India using ARIMA model. Journal of Applied and Natural Science, 12(3): 415 - 421. https://doi.org/10.31018/jans.v12i3.2353

\begin{abstract}
Fish is an essential component of the diet of the most populace in Assam and fish farming has been one of the sources of livelihood in rural areas. Assam ranks first in fish production among North-eastern states of India. However, fish production is not sufficient to meet the demand despite having vast aquatic resources in the state. The present study was undertaken to determine the decadal growth of fish production in the state using the compound growth rate. The study also attempted modelling and forecasting of fish production in Assam using Auto-Regressive Integrated Moving Average (ARIMA) methodology. For the present study, time-series data on fish production in Assam from 1980-81 to 2018-19 was obtained from Directorate of Fisheries, Government of Assam. Data for the period 1980-81 to 2014-15 was utilized to build an ARIMA model and validated through the remaining data from 2015-16 to 2018-19. The best suitable model for the state's fish production was ARIMA $(1,1,0)$ based on values of the model selection criterion. The actual fish production and forecast values using a fitted model were in close agreement. The out-of-sample forecast values of fish production in the state for the subsequent years 2019-20 to 2022-23 showed an increasing trend from 336.97 to 358.21 thousand metric tonnes. Considering the vast aquatic resources in the state, the study calls for serious attention by policymakers, researchers and developmental agencies for harnessing the potential of fisheries resources for making the North-east region self-sufficient in fish production as a whole and Assam in particular.
\end{abstract}

Keywords: ARIMA, Assam, Compound growth rate (CGR), Fish production, Forecast

\section{INTRODUCTION}

India has vast fisheries resources with a contribution from both inland and marine sector. The inland fisheries resources of the country include a length of 0.19 million $\mathrm{km}$ rivers and canals and 6.76 million ha area of reservoirs, ponds and tanks, beels, oxbow lakes and derelict waters. During 2018-19, the annual production of the country was 13.7 million metric tonnes
(MMT) with a contribution of 8.92 MMT (65\%) from the inland sector alone (Economic Survey, 2109). India ranks second in fish production and second-largest aquaculture nation in the world next to China. However, available technologies were demonstrated that inland fish production could easily be enhanced manifolds. Assam occupies a significant position among major inland fish producing states in India. However, 
Assam has the highest fisheries resources as well as fish production among north-eastern states in the country. About 90 per cent population of the state are fish eaters (Das et al., 2017a). Fishery sector provides direct employment in the producing units (primary level) and indirect employment through its ancillaries and associated activities (value chain). The state has vast and varied resources under fisheries of around 2.86 lakh hectares (excluding river fisheries). Floodplain wetlands, locally known as beels, located in Brahmaputra and Barak river basins (Acharjee et al., 2009; Das et al., 2009; Borah et al., 2017; Das et al., 2017a; Das et al., 2018) are an important component of the fisheries of the state with an area of over 100,000 hectares (Kumar et al., 2017a; Nath et al., 2017; Borah et al., 2020; Sarkar et al., 2020). The total fish production in the state was 3.31 lakh metric tonnes (MT) during 2018-19 against the estimated nutritional demand of 3.43 lakh MT (considering per capita fish consumption @11 kg). In spite of having vast aquatic resources and recent technological advances, the fish production from the state in terms of its potential is yet to be achieved. The fishery sector contributed Rs. 475,816 lakhs during 2015-16, Rs. 498,850 lakhs during 201617 (Quick estimates) and Rs. 522,478 lakhs during 2017-18 (advanced estimates) to the State Gross Domestic Product with a growth rate of $4.68 \%$ per year, during the period (Economic Survey Assam, 2018). Proper trend analysis and forecast of fish production is of immense value in an economic system. An unexpected decline or surplus in production can lead to a sharp increase or decrease in prices and has significant social implications as well, as it affects the family and community life of farmers. Impact on the price of an essential commodity has a significant role in determining various economic phenomena. The proper forecast would pave the way for policymakers in formulating appropriate policy measures and ensure profit for the fish farmers.

Compound growth rate (CGR) has been widely used to estimate growth trends in the fisheries sector (Jeyanthi and Nikita, 2012; Debroy et al., 2016 and Sharma, 2017). Previously attempts have been made to forecast fish production using ARIMA models (Paul and Das 2010; Anuja et al., 2017; Kehinde and Joseph 2018; Mah et al., 2018; Mehmood et al., 2020). ARIMA models were also used to obtain a seasonal forecast of fish production in Odisha (Raman et al., 2017). Apart from fisheries, ARIMA models were used for forecasting India's sugarcane productivity (Kumar et al., 2017b), eggs production (Chaudhari and Tingre, 2015) and milk production (Mishra et al., 2020).

Against this backdrop, the present study was carried out to analyze the growth trends of fish production in Assam, a potential state in North-eastern India, and forecast and validate the fish production using Auto-
Regressive Integrated Moving Average (ARIMA) models.

\section{MATERIALS AND METHODS}

Data collection: The time-series data on fish production (in thousand MT) in Assam for a period of 39 years from $1980-81$ to $2018-19$ was obtained from the Directorate of Fisheries, Government of Assam (DoF, 2019) for conducting the present study.

Estimation of compound growth rate (CGR): The CGR of fish production in Assam were estimated by fitting a log-linear model (Salim and Biradar, 2009). The significance of growth rate was tested by applying $t$-test. It works on the null hypothesis that change in fish production in a given year would depend on the fish production in preceding year. The model is expressed as , $y_{t}=A(1+r)^{t}$ or $\ln y_{t}=\alpha+\beta t$ where, $Y_{z}$ is the fish production in the year $t$ for which growth rate is estimated, $A$ is constant, $r$ is rate of annual increment, $\ln A=\alpha$ and $\ln (1+r)=\beta$. Compound growth rate (CGR) was estimated as $r=[\operatorname{antilog}(\beta)-1)] * 100$.

ARIMA Model: Time series data refers to observations on a single phenomenon collected over an equal interval of time. Time series modelling works on the basic assumption that some feature of the past pattern will continue to happen in future. The objective of the present study was to develop a suitable forecast model for describing fish production in Assam. Univariate Box-Jenkin's ARIMA technique, which provides a parsimonious model and lowest forecast error, has been applied for obtaining the same. Mathematically, an ARIMA model with order of autoregression (AR) p, order of differencing $d$, and moving average (MA) order $q$ is denoted by $\operatorname{ARIMA}(p, d, q)$, has the following expression:

$$
\varphi_{p}(B) \nabla^{d} Y_{t}=\theta_{q}(B) \varepsilon_{t}
$$

where, $Y_{t}$ is the fish production at time $t ; \varphi_{p}(B)$ and $\theta_{q}(B)$ are polynomials in f degree $\mathrm{p}$ and $\mathrm{q}$, respectively; $\nabla^{d}=(1-B)^{d}, B$ is backshift operator such that $B Y_{t}=Y_{t-1}$ and $\varepsilon_{t} \sim W N\left(0, \sigma^{2}\right), W . N$. indicating White Noise.

In this approach, the most reliable forecast model is automatically selected from the family of ARIMA models by going through three iterative stages, that is, identification of order of model (through transformation, differencing, Augmented-Dickey-Fuler- ADF unit root stationary test, order determination, analyses of autocorrelations and partial autocorrelations function), estimation of model parameters (using least squares methods), and diagnostic checking for the adequacy of fitted models (Ljung and Box, 1978 statistic- $Q$ for residuals autocorrelations). For identification 
of the best fitted ARIMA models, the fit statistics AICAkaike Information Criterion (Akaike, 1972) and the BIC- Bayesian Information Criterion proposed by Schwartz, 1978 were used. Finally, in the forecasting stage, forecasts of future values of the fish production in Assam were generated using a finalized model. Evaluation of forecast values was carried out with mean absolute error (MAE), mean absolute prediction error (MAPE), and root means square error (RMSE). Box et al. (2007) has given an excellent discussion of different phases of time series approach. In this study, we used PROC ARIMA in SAS ( $v$ 9.2) and forecast package in $R$ ( $v$ 3.5) for model development. A schematic diagram of Box-Jenkins iterative approach to the model building is depicted in Fig. 1 (adapted from Kumar et al., 2017b).

\section{RESULTS AND DISCUSSION}

Growth performance of fish production: We compared the decadal growth performance of fish production in Assam during the period 1980-81 to 2018-19. The whole period was divided into four decades, viz. $1980-81$ to $1989-90$ (Period 1), $1990-91$ to $1999-00$ (Period 2), 2000-01 to 2009-10 (Period 3), and 201011 to 2018-19 (Period 4) to understand the decadal performance. Decadal growth rates of fish production in Assam were depicted in Table 1. The fish production increased from 42.7 thousand MT in 1980-81 to 331.1 thousand MT 2018-19 with an average production of 161.8 thousand MT during the period. The growth rates of fish production were recorded positive and significant $(p<0.05)$ over the decades, with highest growth rate and instability observed in period 2 followed by period 4. Despite the fact that Assam has vast aquatic resources, the growth performance of the fishery sector in the state leaves much to be desired. However, there is a moderate increase in fish production in the last decade. The expansion of area under aquaculture and development of open water fisheries resources (floodplain wetlands locally called beels, reservoirs, etc.) has to become an important option to enhance fish production. Further, derelict water bodies could be an important resource to provide a significant boost to the state's fish production to meet the ever-

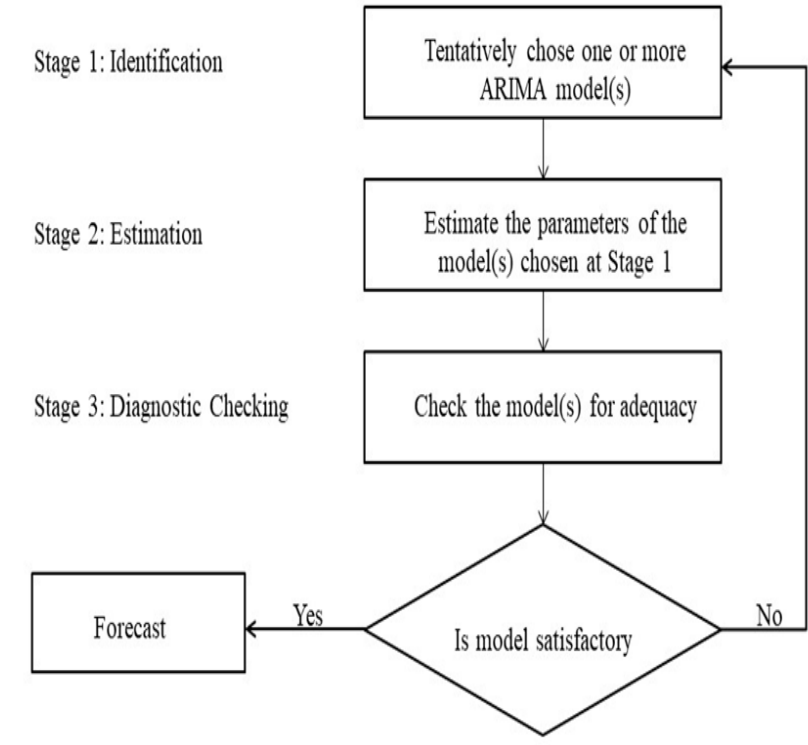

Fig. 1. Stages in Box-Jenkin's iterative approach to the model building (adapted from Kumar et al., 2017b).

increasing demand of growing population and economy. The enormous floodplain wetlands in Brahmaputra basin of Assam has been laying fallow (Jayasankar, 2018). The fish production will increase tremendously by bringing these water bodies under the ambit of culture-based fisheries. According to a study, an expected fish production of 81,900 MT can be realized after intervention through scientific management (enclosure culture and stock enhancement) of open water fisheries resources in the state (Das et al., 2017a, Das et al., 2017b, Das et al., 2018, Sarkar et al., 2020). Hence, the development of these water bodies is one of the focus areas of the government for increasing fish production (DADF, 2019). The fish production in Assam grew at a rate of $5.6 \%$ during the past four decades, indicating there is an untapped growth potential for fish production in the state. In order to tap the vast potential of the fisheries sector, the Centre and State governments have launched programs like "Blue revolution 2.0/ Neel Kranti Mission", "Doubling the farmers' income by 2022" since 201516, "Ghare Ghare Pukhuri Ghare Ghare Maach (fishery in every household)" since 2017-18 and recently launched "Pradhan Mantri Matsya Sampada

Table 1. Descriptive statistics and rate of growth of decadal fish production ('000 MT) in Assam.

\begin{tabular}{lllll}
\hline Decadal period & Mean & SD & CV (\%) & CGR (\%) \\
\hline Period 1 & 50.2 & 6.14 & 12.2 & $3.7^{*}(0.90)$ \\
Period 2 & 143.1 & 25.2 & 17.6 & $6.2^{* *}(0.60)$ \\
Period 3 & 183.7 & 19.2 & 10.5 & $3.3^{*}(0.87)$ \\
Period 4 & 282.7 & 35.6 & 12.6 & $4.7^{*}(0.92)$ \\
Entire Period & 161.8 & 86.2 & 53.3 & $5.6^{*}(0.88)$ \\
\hline
\end{tabular}

Note: $* * *$ indicates significance at $1 \%$ and $5 \%$ level of significance respectively. Figure in parentheses represents value of $\mathrm{R}$-square. 
Table 2. Sample autocorrelation functions (Acf) and partial autocorrelation functions (Pacf) of the original and differenced series.

\begin{tabular}{ccclc}
\hline Lag & $\begin{array}{l}\text { ACF of } \\
\text { the series }\end{array}$ & $\begin{array}{l}\text { PACF of } \\
\text { the series }\end{array}$ & $\begin{array}{l}\text { ACF of the first } \\
\text { differenced series }\end{array}$ & $\begin{array}{l}\text { PACF of the first } \\
\text { differenced series }\end{array}$ \\
\hline 1 & 0.902 & 0.902 & 0.338 & 0.338 \\
2 & 0.803 & -0.062 & 0.110 & -0.005 \\
3 & 0.702 & -0.063 & -0.088 & -0.139 \\
4 & 0.603 & -0.048 & -0.084 & -0.014 \\
5 & 0.508 & -0.044 & -0.110 & -0.067 \\
6 & 0.418 & -0.033 & -0.120 & -0.081 \\
7 & 0.333 & -0.035 & -0.187 & -0.142 \\
8 & 0.258 & -0.010 & -0.171 & -0.090 \\
\hline
\end{tabular}

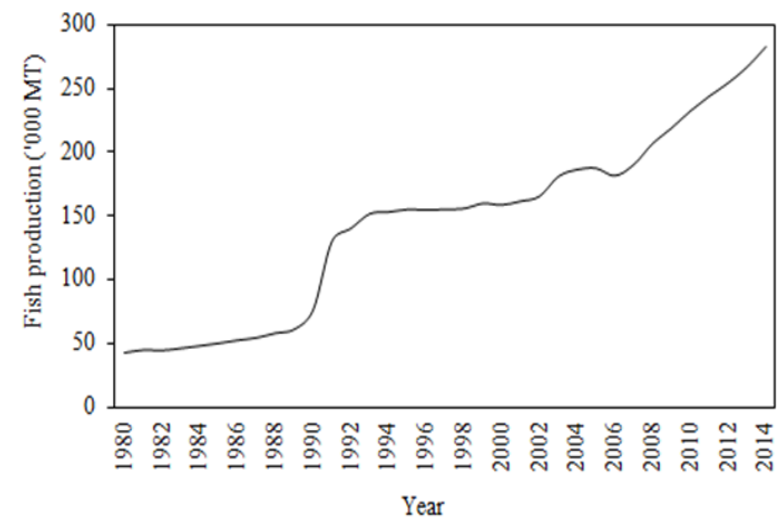

Fig. 2. Fish production in Assam during the period 19802014.

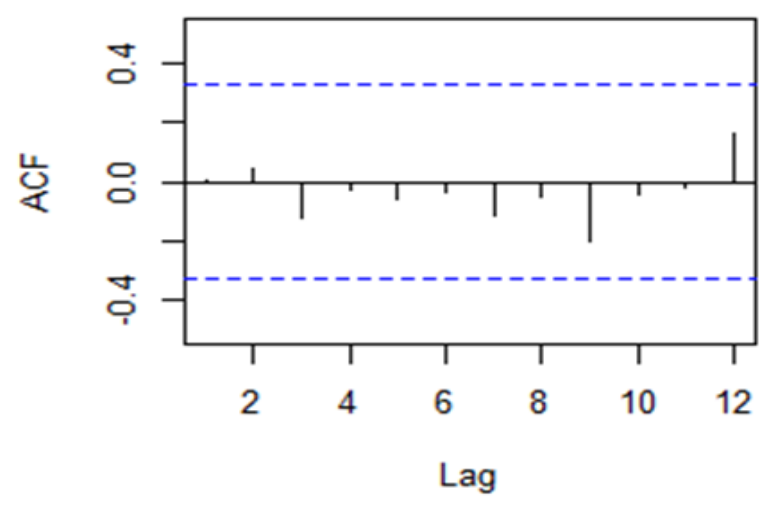

Fig. 4. Plot of ACF and PACF of residuals for fish production.

Yojana (PMMSY)" in 2019-20.

ARIMA Models: This study was undertaken to attempt forecasting the fish production in Assam through the fitting of well-known Box-Jenkin's univariate AutoRegressive Integrated Moving average (ARIMA) model. Time series data on fish production from period 1980-81 to 2018-19 was collected from Directorate of Fisheries, Govt. of Assam (DoF, 2019) for the study. The data from $1980-81$ to $2014-15$ was used to build an ARIMA model and validated through a four year period from 2015-16 to 2018-19.

Fitting of ARIMA Model: First and foremost stage in

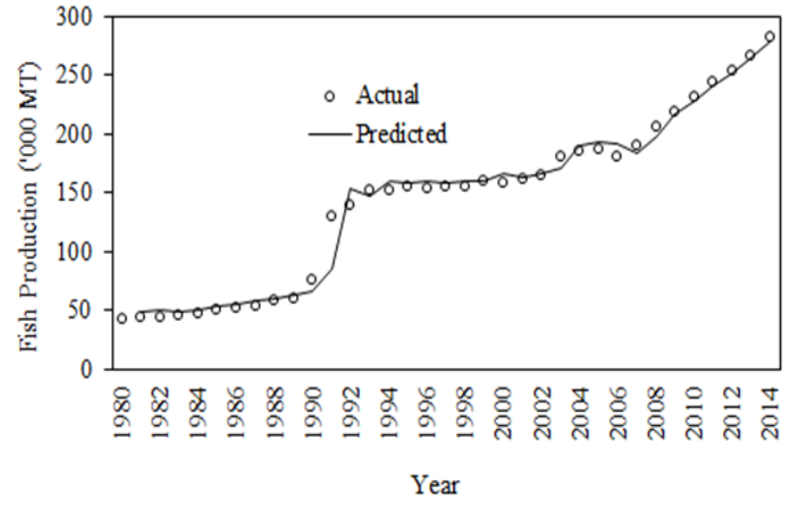

Fig. 3. Observed and fitted values of fish production.

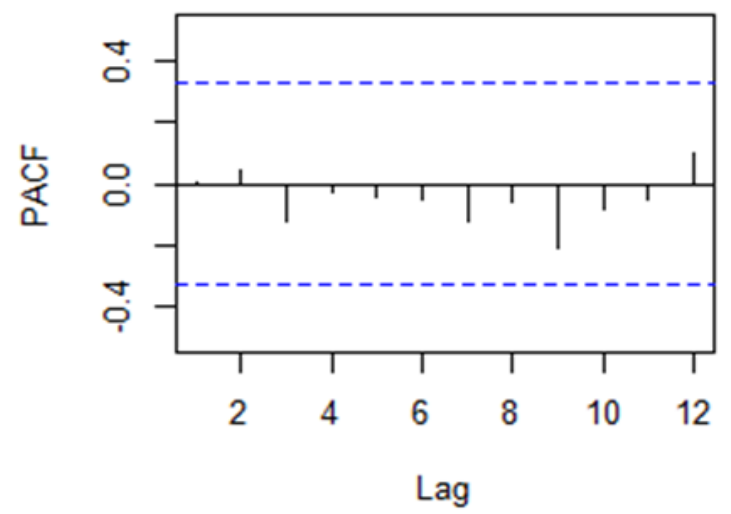

the identification of an ARIMA model was to check whether series is stationary or not. The graph of the time series data (Fig.2) exhibited a linear trend in fish production, indicating that the series was nonstationary. The estimated autocorrelations functions (ACF) and partial autocorrelations functions (PACF) plot of the series up to lag 8 were reported in Table 2. Besides the graph of the original series, the nonstationary behavior was also indicated by the very slow decay of autocorrelation value for the series (Table 2). Augmented Dickey and Fuller (1979) test for unit root was applied for testing the null hypothesis 
Table 3. AIC and BIC values of different ARIMA models for fish production in Assam.

\begin{tabular}{lll}
\hline Model & AIC & BIC \\
\hline ARIMA $(1,1,0)$ & 252.98 & 256.03 \\
ARIMA $(0,1,1)$ & 253.63 & 260.29 \\
ARIMA $(1,1,1)$ & 257.07 & 263.18 \\
ARIMA $(2,1,0)$ & 256.71 & 261.84 \\
ARIMA $(2,1,1)$ & 255.51 & 258.14 \\
\hline
\end{tabular}

Table 4. Parameter estimates of fitted ARIMA $(1,1,0)$ for fish production in Assam.

\begin{tabular}{llll}
\hline Parameter & Estimates & $\begin{array}{l}\text { Standard } \\
\text { Error }\end{array}$ & t-value \\
\hline A.R. lag1 $\left(\varphi_{1}\right)$ & 0.346 & 0.118 & $2.16^{\text {** }}$ \\
Constant & 7.079 & 2.497 & 2.83 \\
\hline
\end{tabular}

Note: ** Significant at $5 \%$ level of significance

$\rho=0$ against alternative $\rho<0$ in the auxiliary regression $\Delta_{1} y_{t}=\rho y_{t-1}+\alpha_{1} \Delta_{1} y_{t-1}+\varepsilon_{t}$. Under null hypothesis, the estimated value of $\rho=-2.236$ was not significant ( $p$-value $=0.48$ ), thereby null hypothesis to be accepted. From the values of ACF, PACF and unit root test, differencing of the fish production data was required to make it stationary.

The first differenced series of original fish production data showed appropriate stationary behaviour. The ACF values of the differenced series were observed to be small and dropped off after lag 1 (Table 2). This suggested that the series was stationary after first difference and hence the value of $d$ was selected as 1 . Since the ACF values have an exponentially decaying pattern and its PACF values cut off to zero after lag 1, suggested an autoregressive (A.R.) model of the order 1. So, $\operatorname{ARIMA}(1,1,0)$ model which contains only one auto regression term $\varphi_{1}$ was selected tentatively. In this study, different auto-regression models up to order 2 were attempted. Based on the minimum values $A I C$ and $B I C$ selection criterion, $\operatorname{ARIMA}(1,1,0)$ was proposed as the best suitable model for fish production in Assam (Table 3). The estimated values of the parameters along with their standard error for the fitted ARIMA $(1,1,0)$ model were presented in Table 4.

The graph of actual data on fish production and predicted values by the fitted model was presented in Fig. 3. The actual and forecast values were in close agreement with each other. The R-square value of the fitted model was 0.91 . Thus, the fitted $\operatorname{ARIMA}(1,1,0)$ model was good and amenable to capture the trend of fish production in Assam.

After model fitting, goodness-of-fit checks for the adequacy of fitted models were performed. A model is said to be statistically adequate if residuals are not auto-correlated. The estimated values of ACF and PACF of residuals of the fitted model were presented graphically in Fig.4, which showed that both ACF and PACF were lying within the $95 \%$ confidence limits. The non-significance of ACF and PACF of residuals showed that residuals were independent. Further, Chisquares test suggested by L-Jung and Box- test using Q-statistics ( L-Jung and Box 1978) for the fitted model was not significant $(p>0.05)$, thereby indicated that the model was able to capture the dependence in time series. Thus, the diagnostic checks confirmed that $\operatorname{ARIMA}(1,1,0)$ was appropriate and parsimonious.

After confirming the validity of the fitted model, it was used for forecasting over the validation period (201519) and reported in Table 5 . The predictive performance of the model was checked by comparing the forecast values against the actual observations. Mean absolute error (MAE), Mean absolute percentage error (MAPE) and Root mean square error (RMSE) were calculated for forecast evaluation. The values of MAE,

Table 5. Forecast of fish production ('000 MT) for fitted ARIMA(1,1,0) model.

\begin{tabular}{llllll}
\hline Year & Actual & Forecast & $\begin{array}{l}\text { Standard error } \\
\text { of forecast }\end{array}$ & Upper & $\begin{array}{c}\text { 95\% Confidence Limits } \\
\text { Lower }\end{array}$ \\
\hline 2015 & 294.2 & 301.011 & 16.2756 & 269.11 & 332.91 \\
2016 & 306.6 & 309.666 & 21.6159 & 266.092 & 350.825 \\
2017 & 327.3 & 317.789 & 29.9868 & 264.016 & 381.562 \\
2018 & 331.1 & 325.883 & 33.4462 & 264.33 & 395.437 \\
2019 & & 336.968 & 36.5866 & 265.259 & 408.676 \\
2020 & & 344.049 & 39.4802 & 266.669 & 421.428 \\
2021 & & 351.128 & 42.1761 & 268.464 & 433.793 \\
2022 & & 358.208 & 44.7105 & 270.577 & 445.839 \\
\hline
\end{tabular}

Note: Year (Example, 2022) denotes financial year (Example, 2022-23). 
MAPE and RMSE for the fitted model were computed as $6.365,2.021$ and 6.816 , respectively. Finally, the above-fitted model was used for forecasting fish production in Assam for the period 2019-20 to 2022-23 (Table 5). An increasing trend was observed for fish production in Assam during the forecasted years. The present nutritional demand of 3.54 lakh tonnes of fish in the state (considering 90\% estimated population in 2020 are fish eaters and per capita fish consumption @ $11 \mathrm{~kg}$ ) may be fulfilled by $2022-23$. However, the present fish production of the state needs to be doubled through a holistic approach to meet the per capita fish consumption of $20 \mathrm{~kg}$ in near future.

\section{Conclusion}

The study showed low, stable growth of fish production in Assam. However, the growth rates were positive over the decades, indicating a healthy trend. The study attempted to develop the model to forecast the fish production in the state using a time-series approach. ARIMA $(1,1,0)$ model was found suitable and amenable to capture the trend of fish production in Assam. The forecasts values by the fitted ARIMA $(1,1,0)$ model showed an increasing trend in fish production of Assam and the state to become selfsufficient in fish production in near future. Considering the vast open water resources in the state, the growth and trend of fish production leave much to be desired. There are substantial opportunities to increase fish production through more productive use of aquatic resources. The fish production can be enhanced considerably by bringing the floodplain wetlands (bee/s) and derelict water bodies under the ambit of culture-based fisheries. Adoption of enclosure culture for raising stocking materials and marketable fish in open waters can enhance fish production. The study calls for serious attention by policymakers, researchers and developmental agencies for harnessing the potential of these resources for making the North-east region selfsufficient in fish production as a whole and Assam in particular.

\section{ACKNOWLEDGEMENTS}

The authors are thankful to the Director, ICAR-Central Inland Fisheries Research Institute, Barrackpore, Kolkata and the Vice-Chancellor, Gauhati University, Guwahati for providing necessary facilities for carrying out this study. The authors also express their indebtedness to Directorate of Fisheries, Govt. of Assam for providing data.

\section{REFERENCES}

1. Acharjee, B., Dutta, A., Sharma, D. K., Das, P. and Behera, B.K. (2009). Ecological status of Deepor Beel, Assam with special reference to its fish and fisheries. In: Kosygin,
L. (ed.), Ecology, Aquatic Bio-resources and conservation of wetlands of North east India, pp. 41-54. Akansha Publishing House, New Delhi (ISBN 978-81-8370-187-7).

2. Akaike, H. (1972). Use of an information theoretic quantity for statistical model identification. In: Proceedings of 5th Hawaii international conference on system sciences, pp. 249-250.

3. Anuja, A., Yadav, V. K., Bharti, V. S. and Kumar, N. R. (2017). Trends in marine fish production in Tamil Nadu using regression and autoregressive integrated moving average (ARIMA) model. J. Appl. \& Nat. Sci., 9(2): $653-$ 657, doi.org/10.31018/jans.v9i2.1252.

4. Borah S., Bhattacharjya B.K., Saud B.J., Yadav A.K., Debnath D., Yengkokpam S., Das P., Sharma N., Singh N. S. and Sarma K. K. (2017). Length-weight relationship of six indigenous fish species from Deepor beel, a Ramsar site in Assam, India. Journal of Applied Ichthyology, 33: 655-657, doi.org/10.1111/jai.13348.

5. Borah, S., Das, P., Bhattacharjya, B. K., Yadav, A. K. Saud, B. J. and Das, B. K. (2020). A report on the occurrence of Bangana dero (Hamilton, 1822) from Deepor beel (Ramsar site no. 1207), Brahmaputra valley, Assam. J. Appl. \& Nat. Sci., 12(2): 202-206, doi.org/10.31018/ jans.vi.2288.

6. Box, G. E. P., Jenkins, G. M. and Reinsel, G. C. (2007). Time-Series Analysis: Forecasting and Control. Revised edition, Holden Day.

7. Chaudhari, D. J. and Tingre, A. S. (2015). Forecasting eggs production in India. Indian Journal of Animal Research, 49(3): 367-372.

8. DADF (2019). Annual report 2018-19. Department of Animal Husbandry, Dairying and Fisheries, Ministry of Agriculture and Farmers Welfare, Govt. of India (http:// www.dahd.nic.in).

9. Das, P., Behera, B.K. and Ngachan, S.V. ( 2009). Beels of Assam - an overview. In: Kosygin, L. (ed.), Ecology, Aquatic Bio-resources and conservation of wetlands of North east India, pp. 29-40. Akansha Publishing House, New Delhi (ISBN 978-81-8370-187-7).

10.Das, B. K., Bhattacharjya, B. K., Borah, S., Das, P., Debnath, D., Yengkokpam, S., Yadav, A. K., Sharma, N., Singh, N. S., Pandit, A., Ekka, A., Mishal, P., Karnatak, G., Kakati, A., Saud, B. J. and Das, S. S. (2017a). Roadmap for development of open water fisheries in North-eastern states, pp. 120. ICAR-CIFRI, Barrackpore.

11.Das, P., Bhattacharjya, B.K., Yadav, A.K., Debnath, D., Yengkokpam, S., Sarma, K.K., Gogoi, P., Sharma, N., Borah, S., Kakati, A., Ray, B. C. and Das, B. K. (2017b). Impact of fish stock enhancement through in-situ raising of stunted carp fingerlings in pens on fish production. In: Thomas, S. N., Rao, M. B., Madhu, V. R., Asha, K.K., Bisni, P.K., Viji, P., Sajesh, V.K., Jha, P.N. (eds.), Fostering Innovations in Fisheries and Aquaculture: Focus on sustainability and safety- Book of Abstracts, p.228. $11^{\text {th }}$ Indian Fisheries and Aquaculture Forum, ICAR-CIFT, Kochi, India.

12.Das, P., Borah, S., Yadav, A. K., Bhattarcharjya, B. K. and Das, B. K. (2018). Open-water fisheries of Assam and strategies for its development. Fishing Chimes, 38 (1and 2): 17-28.

13.Debroy, P., Krishnan, M., Upadhyay, A. D., Ramasubra- 
manian, V., Criddle, K. R., Kiresur, V. R. and Datta, S. K. (2016) Resource distribution, growth and strategies for enhancing fish production in north-eastern states of India. Indian J. Fish., 63(2): 1-7.

14.DoF (2019). Directorate of Fisheries (DoF), Department of Fisheries, Govt. of Assam, India.

15.Economic Survey Assam (2018). Economic Survey Assam, 2017-18. Transformation and Development Department, Directorate of Economics and Statistics, Government of Assam. pp.302.

16.Economic Survey (2019). Economic Survey 2018-19, Vol. 2. Department of Economic Affairs, Ministry of Finance, Govt. of India. pp.468.

17.Nath, K. D., Borah, S., Yadav, A. K., Bhattacharjya, B. K., Das, P., Deka, P. M., Darngawn, O. and Nath, D. V. D. (2017). Length-weight and length-length relationship of four native fish species from Barak River, Assam, India. Journal of Experimental Zoology, India, 20 (2): 977979.

18.Kehinde, O. H. and Joseph, G. E. (2018). Time series modelling for forecasting artisanal fish production in $\mathrm{Ni}$ geria. Int. J. Adv. Multidiscip. Res., 5(7): 10-17.

19.Kumar, J., Yadav, A. K. and Bhattacharjya, B. K. (2017a). A comparative analysis of phytoplankton diversity and abundance during monsoon season in selected beels (wetlands) of Assam, India. J. Appl. Nat. Sci., 9(4): 2285-2290, doi.org/10.31018/jans.v9i4.1525.

20.Kumar, M., Raman, R. K. \& Kumar, S. (2017b). Sugarcane productivity in Bihar: A forecast through ARIMA model. Int. J. Pure App. Biosci., 5(6): 1042-1051, doi.org/10.18782/2320-7051.5838.

21.Jayasankar, P. (2018). Present status of freshwater aquaculture in India - A review. Indian J. Fish., 65(4): 157-165.

22.Jeyanthi, P. and Nikita, G. (2012). Growth and instability in Indian frozen scampi export. Fishery Tech., 49: 187192.

23.Ljung, G. M. and Box, G. E. P. (1978). On a measure of lack of fit in time series models. Biometrika, 65: 297-303.

24.Mah, P. J. W., Zali, N. N. M., Ihwal, N. A. M. and Aazizan, N. Z. (2018). Forecasting fresh water and marine fish production in Malasiya using ARIMA and ARFIMA models. Malaysian Journal of Computing, 3(2): 81-92.

25.Mehmood, Q., Sial, M. H., Sharif, S., Hussain, A., Riaz, M. and Sahneen, N. (2020). Forecasting the fisheries production in Pakistan for the year 2017-26, using BoxJenkin's methodology. Pak. J. Agri. Res., 33(1): 140-145.

26.Mishra, P., Fatih, C., Niranjan, H. K., Tiwari, S., Devi, M. and Dubey, A. (2020). Modelling and forecasting of filk production in Chhattisgarh and India. Indian Journal of Animal Research, doi.org/10.18805/ijar.B-3918.

27.Paul, R. K. and Das, M. K. (2010). Statistical modelling of Inland fish production in India. Journal Inland Fisheries Society of India, 42(2): 1-7.

28.Raman, R. K., Sathianandan, T. V., Sharma, A. P. and Mohanty, B. P. (2017). Modelling and Forecasting Marine Fish Production in Odisha. National Academy Science Letters, 40(6): 393-397, doi.org/10.1007/s40009-017-0581 -2 .

29.Salim, S. S. and Biradar, R. S. (2009), Indian shrimp trade: reflections and prospects in the post WTO era. Asian Fisheries Science, 22: 805-821.

30.Sarkar, U. K., Mishal P., Borah, S., Karnatak, G., Chandra, G., Kumari, S., Meena, D. K., Debnath, D., Yengkokpam, S., Das, P., Debroy, P., Yadav, A. K., Aftabuddin, Md., Gogoi, P., Pandit, A., Bhattacharjya, B. K., Tayung, T., Lianthuamluaia, L. and Das, B. K. (2020). Status, potential, prospects and issues of floodplain wetland fisheries in India: Synthesis and review for sustainable management. Reviews in Fisheries Science and Aquaculture, doi.org/10.1080/23308249.2020.1779650.

31.Schwartz, G. (1978). Estimating the dimension of a model. Annals of Statistics, 6: 461-464

32.Sharma, H. (2017). Growth and instability of inland fish production in India. Fishery Tech., 54: 151-161. 